\title{
Low-Temperature Growth of AIN Films on Magnetostrictive Foils for High-Magnetoelectric-Response Thin-Film Composites
}

Tai Nguyen, Yves Fleming, Philipp Bender, Patrick Grysan, Nathalie Valle, Brahime El Adib, Noureddine Adjeroud, Didier Arl, Mélanie Emo, Jaafar Ghanbaja, Andreas Michels, and Jérôme Polesel-Maris*

Cite This: ACS Appl. Mater. Interfaces 2021, 13, 30874-30884

Read Online

ACCESS | Lلll Metrics \& More | 回 Article Recommendations | sl Supporting Information

ABSTRACT: This study reports a strong ME effect in thin-film composites consisting of nickel, iron, or cobalt foils and $550 \mathrm{~nm}$ thick AlN films grown by PE-ALD at a (low) temperature of 250 ${ }^{\circ} \mathrm{C}$ and ensuring isotropic and highly conformal coating profiles. The AlN film quality and the interface between the film and the foils are meticulously investigated by means of high-resolution transmission electron microscopy and the adhesion test. An interface (transition) layer of partially amorphous $\mathrm{Al}_{x} \mathrm{O}_{y} / \mathrm{AlO}_{x} \mathrm{~N}_{y}$ with thicknesses of 10 and $20 \mathrm{~nm}$, corresponding to the films grown on $\mathrm{Ni}, \mathrm{Fe}$, and Co foils, is revealed. The AlN film is found to be composed of a mixture of amorphous and nanocrystalline grains at the interface. However, its crystallinity is improved as the film

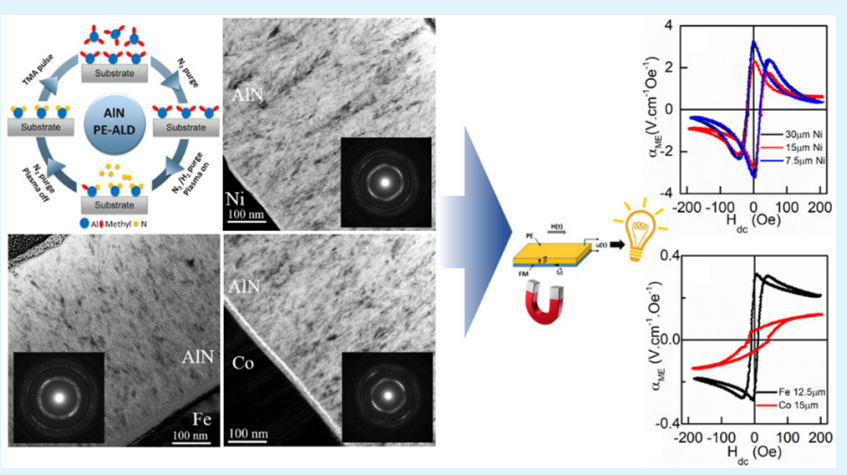
grew and shows a highly preferred (002) orientation. High selfbiased ME coefficients $\left(\alpha_{\mathrm{ME}}\right.$ at a zero-bias magnetic field) of $3.3,2.7$, and $3.1 \mathrm{~V} \cdot \mathrm{cm}^{-1} \cdot \mathrm{Oe}^{-1}$ are achieved at an off-resonance frequency of $46 \mathrm{~Hz}$ in AlN/Ni thin-film composites with different $\mathrm{Ni}$ foil thicknesses of 7.5, 15, and $30 \mu \mathrm{m}$, respectively. In addition, magnetoelectric measurements have also been carried out in composites made of $550 \mathrm{~nm}$ thick films grown on $12.5 \mu \mathrm{m}$ thick Fe and $15 \mu \mathrm{m}$ thick Co foils. The maximum magnetoelectric coefficients of AlN/Fe and AlN/Co composites are 0.32 and $0.12 \mathrm{~V} \cdot \mathrm{cm}^{-1}$. $\mathrm{Oe}^{-1}$, measured at $46 \mathrm{~Hz}$ at a bias magnetic field $\left(H_{\mathrm{dc}}\right)$ of 6 and $200 \mathrm{Oe}$, respectively. The difference of magnetoelectric transducing responses of each composite is discussed according to interface analysis. We report a maximum delivered power density of $75 \mathrm{nW} /$ $\mathrm{cm}^{3}$ for the $\mathrm{AlN} / \mathrm{Ni}$ composite with a load resistance of $200 \mathrm{k} \Omega$ to address potential energy harvesting and electromagnetic sensor applications.

KEYWORDS: magnetoelectric effect, thin-film magnetoelectric composites, AlN thin film, low-temperature process, conformal coatings, PE-ALD, interface

\section{INTRODUCTION}

The simultaneous exhibition of ferroelectricity (piezoelectricity) and ferromagnetism (anti-, ferrimagnetism) has received significant attention for both fundamental and practical purposes. This is because the ferroelectric properties can be manipulated by an external magnetic field or the magnetic properties can be controlled by an electrical field or vice versa. ${ }^{1-6}$ In multiferroic-based applications, the coexistence of ferroelectricity (PE) and ferromagnetism (FM) is not enough. In fact, a strong coupling of the two phenomena, the so-called magnetoelectric (ME) coupling effect, is highly demanded. The first observation of the ME coupling effect was in $\mathrm{Cr}_{2} \mathrm{O}_{3}$, even though the $\mathrm{Cr}_{2} \mathrm{O}_{3}$ compound is not multiferroic. ${ }^{7}$ Some transition metal compounds, such as bismuth ferrite $\left(\mathrm{BiFeO}_{3}\right)$, bismuth manganite $\left(\mathrm{BiMnO}_{3}\right)$, terbium manganite $\left(\mathrm{TbMnO}_{3}\right)$, and $\mathrm{LuFe}_{2} \mathrm{O}_{4}$, and so on, possess both ferroelectric and ferromagnetic properties. However, the mechanisms driving multiferroicity are unique and specific for each compound. In
$\mathrm{BiFeO}_{3}$, it is believed that the mechanism governing multiferroicity comes from two different cations; the off-centring movement of the $\mathrm{Bi}^{3+}$ ion with the "lone pair" electrons in the $6 \mathrm{~s}$ orbital induces ferroelectricity, whereas a robust antiferromagnetism is given by the $3 \mathrm{~d}$ electrons of the $\mathrm{Fe}$ ion $\left(\mathrm{Fe}^{3+}\right.$ and/or $\left.\mathrm{Fe}^{2+}\right) .{ }^{8,9}$ Meanwhile, charge ordering occurring in a ferrimagnetic $\mathrm{LuFe}_{2} \mathrm{O}_{4}$ is believed to be likely to produce ferroelectricity. ${ }^{10-12}$ Some other mechanisms have triggered multiferroicity, such as geometric ferroelectricity in hexagonal $\mathrm{RMnO}_{3}(\mathrm{R}=\mathrm{Sc}, \mathrm{Y}, \text { In, or } \mathrm{Dy}-\mathrm{Lu})^{13,14}$ or spin-driven

Received: May 6, 2021

Accepted: June 1, 2021

Published: June 22, 2021 
mechanisms as present in $\mathrm{Cr}_{2} \mathrm{BeO}_{4}$ or in orthorhombic $\mathrm{TbMnO}_{3}{ }^{15-18}$ Unfortunately, the $\mathrm{ME}$ coupling effect of these single-phase multiferroic materials is often too weak and/or at very low temperatures, which impedes practical applications.

Alternatively, ME composites open a pathway to outweigh the above-mentioned disadvantages of single-phase multiferroics by connecting ferroelectric (piezoelectric) and ferromagnetic (magnetostrictive) materials into an $\mathrm{ME}$ composite. ${ }^{19}$ In these composites, the ME coupling is governed by a strain-mediated interaction between the two phases, i.e., the strain induced in the ferromagnetic phase is mechanically transferred through to the ferroelectric phase via the interface. The notation, such as $1-3,0-3$, and $2-2$, is used to classify the structure of an ME composite in which the number describes the dimensional geometry of each phase. ${ }^{20}$ Various deposition techniques, such as electrochemical coating, ${ }^{21,22}$ magnetron sputtering, ${ }^{23,24}$ pulsed laser deposition (PLD), ${ }^{25-29}$ spark plasma sintering, ${ }^{30}$ molecular beam epitaxy (MBE), ${ }^{31,32}$ and metal-organic chemical vapor deposition (MOCVD), ${ }^{33}$ were used to fabricate ME composites.

On one hand, a 1-3 composite consists of a single-phase nanopillar (denoted 1) embedded into a matrix of another phase (denoted 3). Intensive work has been carried out to design composites with a strong ME effect in both ceramic and thin-film composites. Bulk ME ceramic composites, such as $\mathrm{BaTiO}_{3}-\mathrm{Ni}(\mathrm{Co}, \mathrm{Mn}) \mathrm{Fe}_{2} \mathrm{O}_{4}{ }^{34}$ and $(\mathrm{Sr}, \mathrm{La}) \mathrm{PbZrTiO}_{3}-$ $\left(\mathrm{Ni}_{0.7} \mathrm{Zn}_{0.3}\right) \mathrm{Fe}_{2} \mathrm{O}_{4},{ }^{35}$ were synthesized via cosintering at high temperatures. Zavaliche and co-workers ${ }^{36}$ demonstrated the $\mathrm{ME}$ effect in $\mathrm{CFO}$ nanopillars embedded in a $\mathrm{BiFeO}_{3}$ matrix. However, the ME effect in these bulk composites was very weak because of interfacial interdiffusion and/or interface reactions, leading to a high leakage current and poor coupling. This poor coupling generated is due to the high-temperature treatment for fabrication with a difference in thermal expansion between the two bulk phases inducing delamination/cracks, thus reducing the coupling. The $0-3$ ceramic composites face similar issues and a high leakage current in composites, which is due to the electrically conductive constituent of the magnetostrictive phase that is embedded in the ferroelectric matrix with a high particle density. By utilizing the sol-gel technique, Wan et al. ${ }^{37}$ reported $0-3$ composite films by dispersing $\mathrm{CoFe}_{2} \mathrm{O}_{4}$ (CFO) nanoparticles in $\mathrm{Pb}(\mathrm{Zr}, \mathrm{Ti}) \mathrm{O}_{3}$ (PZT). Exploiting PLD, Ryu et al. ${ }^{28}$ grew PZT/CoFe $\mathrm{O}_{4}$ composites on $\mathrm{SrTiO}_{3}$ substrates. Unfortunately, the $\mathrm{ME}$ coefficient was limited because of a poor interface between the two phases and a high leakage current and/or a strong clamping effect induced by the substrates. On the other hand, a high ME coefficient in the 2-2 bulk laminate composites is expected because of the elimination of the leakage current. $^{38-42}$ However, in these bulk laminate composites, the use of epoxy to connect the two layers as well as the need of additional electrodes significantly affect the ME response of the composites with poor coupling interfaces between consecutive layers. $^{43-45}$

Compared to bulk ME composites, thin-film composites have superior transduction properties from a combination of the layers at the atomic level, precise control of the lattice mismatch between materials, and the possibility of growing epitaxial composite films. In addition, a thin-film composite facilitates its ability to integrate into microelectronics and microelectromechanical systems (MEMS). Recently, Gupta et $\mathrm{al}^{29}$ reported a giant ME coefficient of $130.5 \mathrm{~V} \cdot \mathrm{cm}^{-1} \cdot \mathrm{Oe}^{-1}$ in
$\mathrm{PZT} / \mathrm{Ni}$ composite grown by PLD. However, its ME response is only effective after a nonobvious supplementary stage of poling of the PZT layer. Furthermore, the authors claimed nickel oxide was formed due to the high deposition temperature of $\mathrm{PZT}$ at $800{ }^{\circ} \mathrm{C}$, which degraded the performance of $\mathrm{Ni}$ in the composites.

In the current study, we aimed at applying highly conformal AlN thin films made by PE-ALD to different magnetostrictive materials to overcome the issues of the thin-film ME composites processing and the interface between the two phases. Commercial $\mathrm{Ni}, \mathrm{Fe}$, and $\mathrm{Co}$ foils with different thicknesses were exploited as a magnetostrictive layer due to their nonzero and moderate piezomagnetic coefficient. ${ }^{46}$ Furthermore, these were shown to have a high electrical conductivity, simplifying electrode interfacing. AlN films grown directly on the foils by PE-ALD at a low temperature of $250^{\circ} \mathrm{C}$ were part of a piezoelectric layer. Our earlier work ${ }^{47,48}$ demonstrated that even at a low deposition temperature, AlN films show good piezoelectric properties with a direct piezoelectric coefficient $e_{31, \mathrm{f}}$ of $0.37 \mathrm{C} / \mathrm{m}^{2}$. Compared to other coating methods, such as spin coating, sputtering, CVD, and PLD, utilizing the PE-ALD technique to design ME composites is believed to ensure an excellent interface owing to its low-temperature processes and highly conformal coating profile. Therefore, the effect of differences in lattice mismatch, thermal expansion, atomic interdiffusion, and morphology quality between the two phases can be mitigated. As a result, a strong ME coupling in these composites is expected.

\section{EXPERIMENTAL SECTION}

The AlN thin film was synthesized with a commercial plasmaenhanced atomic layer deposition PE-ALD reactor (TFS-200, Beneq, Finland) using standard precursors, such as trimethyl aluminum $\mathrm{Al}_{2}\left(\mathrm{CH}_{3}\right)_{6}$ (TMA, Strem Chemicals, Inc., France), and a mixture of $\mathrm{N}_{2}: \mathrm{H}_{2}$ :Ar gases with a flow ratio of $100 \mathrm{sccm} / 80 \mathrm{sccm} / 30 \mathrm{sccm}$. The AlN films presented in this study were grown by 5000 cycles to obtain a $550 \mathrm{~nm}$ thick film. Details in the optimization of AlN film growth can refer to our previous work. ${ }^{47}$ The films were grown at a temperature of $250{ }^{\circ} \mathrm{C}$ on three different substrates: (1) $2 \times 2 \mathrm{~cm}^{2} \mathrm{Ni}$ (NI000270), Fe (FE000160), and Co (CO000170) foils (Goodfellow $\mathrm{GmbH}$, Germany), (2) $150 \mathrm{~nm}$ thick nickel-coated silicon substrates by sputtering (Baltec Med-020 high vacuum coating system, Ni target purity level of $99.999 \%$, reference NI000565, Goodfellow GmbH, Germany), and (3) pristine (100) silicon substrates $\left(1 \times 1 \mathrm{~cm}^{2}\right.$ pieces of a single-crystal $\mathrm{Si}(100)$ wafer, grade Monitor, Siegert $\mathrm{GmbH}$, Germany). Pristine Si wafers were used for measuring the thickness of the different AlN film deposits.

The thickness of the AlN films was verified by ellipsometry (J. A. Woolam Ellipsometer). The film crystal structure was examined by Xray diffractometry using a PIXcel ${ }^{3 \mathrm{D}}$ detector (PANalytical X'Pert Pro) in grazing incidence (GI-XRD) configuration with an incidence angle of $\omega=0.5^{\circ}$. Transmission electron microscopy (TEM) and scanning transmission electron microscopy (STEM) investigations were carried out using a JEOL JEM-ARM 200F Cold FEG operating at $200 \mathrm{kV}$ and equipped with a spherical aberration (Cs) probe and image correctors (point resolution $0.12 \mathrm{~nm}$ in TEM mode and $0.078 \mathrm{~nm}$ in STEM mode). Electron energy-loss (EEL) spectra were collected for O K, Ni $\mathrm{L} 2,3$, Fe L2,3, Co L2,3, N K, and Al K edges in STEM mode. TEM lamellas were prepared by means of a FIB/SEM FEI Helios NanoLab $600 \mathrm{i}$ equipped with a platinum gas injection system.

The tape test following the ASTM D3359 standard" ("Standard Test Methods for Measuring Adhesion by Tape Test") was performed to evaluate the adhesion between the films and the foils. Details of the test method are found in Figure S1 in the Supporting Information.

The topographic structure was acquired by commercial atomic force microscopy (AFM Innova, Bruker Inc., Santa Barbara) in 
tapping mode by maintaining the amplitude of the cantilever first resonance constant. Images were taken over $2 \times 2 \mu \mathrm{m}^{2}$ at a scan rate of $1 \mathrm{~Hz}$. The tips used were denominated HQ:NSC/Hard (MikroMasch, Bulgaria), Diamond-like carbon-coated, with a nominal cantilever stiffness of $40 \mathrm{~N} / \mathrm{m}$ and an apex diameter of below $20 \mathrm{~nm}$.

Dynamic-secondary ion mass spectrometry (D-SIMS, CAMECA SC-Ultra) was used to analyze the elemental composition of the films grown. The depth profiles were acquired with a $\mathrm{Cs}^{+}$bombardment operating at $1 \mathrm{keV}$ and a $10 \mathrm{nA}$ primary ion beam scanned over an area of $250 \times 250 \mu \mathrm{m}^{2}$. A thin gold layer was added to the top surface of the sample to allow charge evacuation during ionic bombardment. In addition, an electron gun was used to ensure charge compensation.

For the piezoelectric characterization, AlN films were deposited on a silicon wafer with a $150 \mathrm{~nm}$ thick nickel layer as the bottom electrode. Thereafter, a $100 \mathrm{~nm}$ aluminum layer was sputtered on top of the deposit as a top electrode. The specific cantilevers for the fourpoint bending (4-PB) characterization, in order to measure the effective transverse piezoelectric coefficient $\mathrm{e}_{31, \mathrm{f}}$ of the AlN films, were fabricated using laser lithography and wet-etching processes according to the protocol of $\mathrm{K}$. Prume et al. ${ }^{50}$ The magnetization measurement was performed at room temperature with a vibrating sample magnetometer (VSM, Cryogenic, UK) with a magnetic field sweep from -4 to $4 \mathrm{~T}$. The ME coefficient was measured with an in-house magnetoelectric testing bench (Figure S2, Supporting Information) following the dynamic method as described by Vidal and coworkers. ${ }^{51}$ The dynamic method exhibits several advantages compared to the static and quasi-static methods owing to a very efficient reduction of the electronic noise thanks to the phase-sensitive detection by a lock-in amplifier and elimination of the problem of charge accumulation observed for certain ceramics. ${ }^{51}$ Prior to measurement, a $100 \mathrm{~nm}$ thick $\mathrm{Al}$ metal as the top electrode was deposited over $0.3 \times 0.3 \mathrm{~cm}^{2}$ on AlN/Ni composites. The ME voltage, measured between the aluminum top electrode and the nickel bottom electrode, was extracted using a lock-in amplifier (SR865A, 4 $\mathrm{MHz}$ DSP) where composites were exposed to a bias dc magnetic field $(\mathrm{Hdc})$ from an electromagnet varying from -200 to $200 \mathrm{Oe}$ superimposed with a small ac magnetic field $\left(H_{\mathrm{ac}}\right)$ from Helmholtz coils at an amplitude of 8.5 Oe at a constant frequency of $46 \mathrm{~Hz}$. Then, the ME coefficient was calculated using the following equation $^{51} \alpha_{\mathrm{ME}}=\frac{V \text { output }}{t H_{a c}}$, where $t$ is the thickness of the piezoelectric layer (in the thin-film composites) and $V_{\text {output }}$ is the ME voltage extracted in the piezoelectric layer. Both forward $\left(-H_{\mathrm{dc}} \rightarrow 0 \rightarrow+H_{\mathrm{dc}}\right)$ and backward $\left(+\mathrm{H}_{\mathrm{dc}} \rightarrow 0 \rightarrow-H_{\mathrm{dc}}\right)$ measurements were acquired. The power density was calculated by dividing the output power by the device volume.

The raw/processed data required to reproduce these findings can be shared on reasonable request.

\section{RESULTS AND DISCUSSION}

Figure 1 shows the GI-XRD $\left(\omega=0.5^{\circ}\right)$ patterns of $550 \mathrm{~nm}$ thick AlN films grown on 30, 12.5, and $15 \mu \mathrm{m}$ thick Ni, Fe, and Co foils, respectively. The AlN film on $\mathrm{Ni}$ and $\mathrm{Fe}$ exhibits a highly (002)-preferred orientation; meanwhile, the (100) and (002) orientations are observed in the film grown on the Co surface. No formation of metal-oxide phases such as $\mathrm{Ni}_{x} \mathrm{O}_{y}$ and $\mathrm{Co}_{x} \mathrm{O}_{y}$ is detected. It is noted that the strong noise intensity background in the GI-XRD data for $\mathrm{Fe}$ and Co is due to a strong fluorescence of these elements. ${ }^{52}$

The topography of the AlN film surfaces on $\mathrm{Ni}, \mathrm{Fe}$, and $\mathrm{Co}$ foils was measured by AFM on Figure $2 \mathrm{a}, 2 \mathrm{~d}$, and $2 \mathrm{~g}$, respectively. The surface roughness was about 38,8 , and 15 $\mathrm{nm}$ for the films grown on $\mathrm{Ni}, \mathrm{Fe}$ and $\mathrm{Co}$, respectively. The grain-diameter distribution is obtained from particle analysis of the topography images by a watershed detection method processed under Mountain SPIP software (Digital Surf, France). The particle segmented images and its grain-diameter histogram (the inset) are shown in Figure $2 \mathrm{~b}, 2 \mathrm{e}$, and $2 \mathrm{~h}$ and

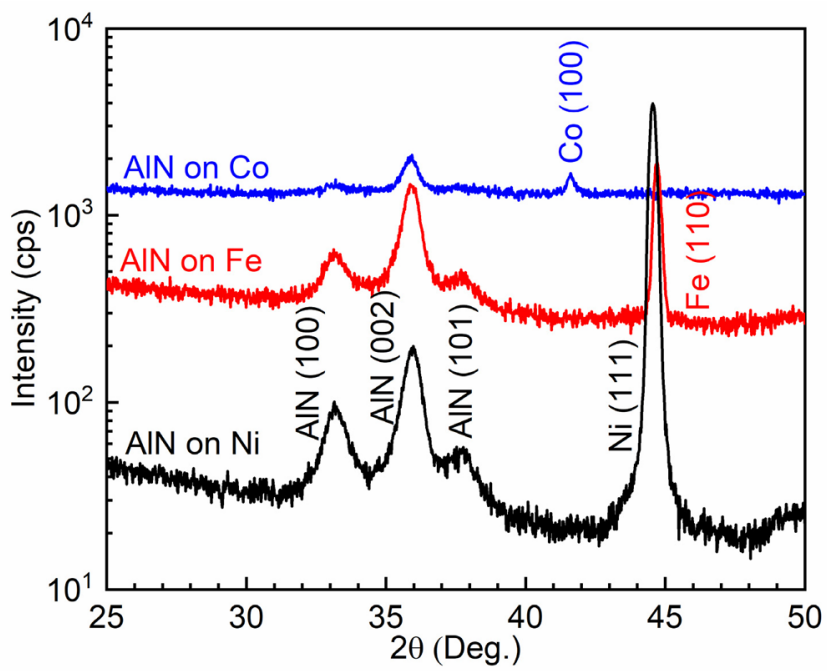

Figure 1. GI-XRD $\left(\omega=0.5^{\circ}\right)$ patterns of a $550 \mathrm{~nm}$ thick AlN film deposited on $30 \mu \mathrm{m}$ thick Ni, $12.5 \mu \mathrm{m}$ thick Fe, and $15 \mu \mathrm{m}$ thick Co foils.

Figure $2 \mathrm{c}, 2 \mathrm{f}$, and $2 \mathrm{k}$. The mean diameter of the grains extracted was $77 \pm 20,82 \pm 32$, and $56 \pm 20 \mathrm{~nm}$ for the AlN films grown on $\mathrm{Ni}, \mathrm{Fe}$, and $\mathrm{Co}$ foils, respectively.

Figure 3 presents TEM observations in a cross-section for AlN films grown on a $30 \mu \mathrm{m}$ thick $\mathrm{Ni}$ foil. The interface between AlN and $\mathrm{Ni}$ is clear, and no delamination is observed, as shown in the TEM bright-field (BF) and dark-field (DF) micrographs (Figure $3 \mathrm{a}$ and $3 \mathrm{~b}$ ). The inserted selected area electron diffraction (SAED) pattern in Figure 3a shows a ring at a $d_{h k l}$ distance of $0.248 \mathrm{~nm}$, confirming the (002)-preferred orientation of the AlN film in accordance with the XRD data (Figure 1). The AlN film presents a columnar structure with amorphous regions and nanocrystalline grains $(20-30 \mathrm{~nm})$.

High-resolution TEM (HR-TEM) was performed to further study the interface between $\mathrm{AlN}$ and $\mathrm{Ni}$ as well as the crystallinity of the AlN film. Figure $3 c$ shows an HR-TEM image and SAED pattern accompanied by fast-Fourier transform (FFT) observed at the interface. Notably, a transition layer of approximately $10 \mathrm{~nm}$ is observed in the AlN layer. The SAED reveals that the crystallinity of AlN at the interface is poor, highly defective, and disordered; however, at the top layer the crystallinity of AIN is highly improved, as illustrated in Figure $3 \mathrm{~d}$ with the SAED pattern. This evolution of the film crystallinity has been reported in our previous study ${ }^{47}$ and by Schneider and co-workers. ${ }^{53}$ It results from the initial inhomogeneous growth regime, which however becomes less effective when the film is thicker. STEM-EELS (Figure $3 e-h)$ was carried out to study the chemical composition and elemental diffusion at the interface and the origin of the transition layer. No significant $\mathrm{Ni}$ and $\mathrm{Al} / \mathrm{N}$ diffusion is detected through the interface. Significant amounts of $\mathrm{O}, \mathrm{Al}$, and $\mathrm{N}$ in the transition layer are observed, implying that the transition layer is amorphous with $\mathrm{Al}_{x} \mathrm{O}_{y}$ oxides and a potential oxynitride forms $\mathrm{AlO}_{x} \mathrm{~N}_{y}$. It is worth noting that a remarkable amount of oxygen is also observed in the AlN film that is coincident with our previous report, ${ }^{47}$ showing that about 6 atom $\%$ of $\mathrm{O}$ was presented in the AlN film. No formation of $\mathrm{Ni}_{x} \mathrm{O}_{y}$ has been detected.

Furthermore, Figures 4 and 5 present TEM observations in a cross-section for AlN films grown on $\mathrm{Fe}$ and Co foils, respectively. Similarly to the AlN film grown on Ni foil, AlN 

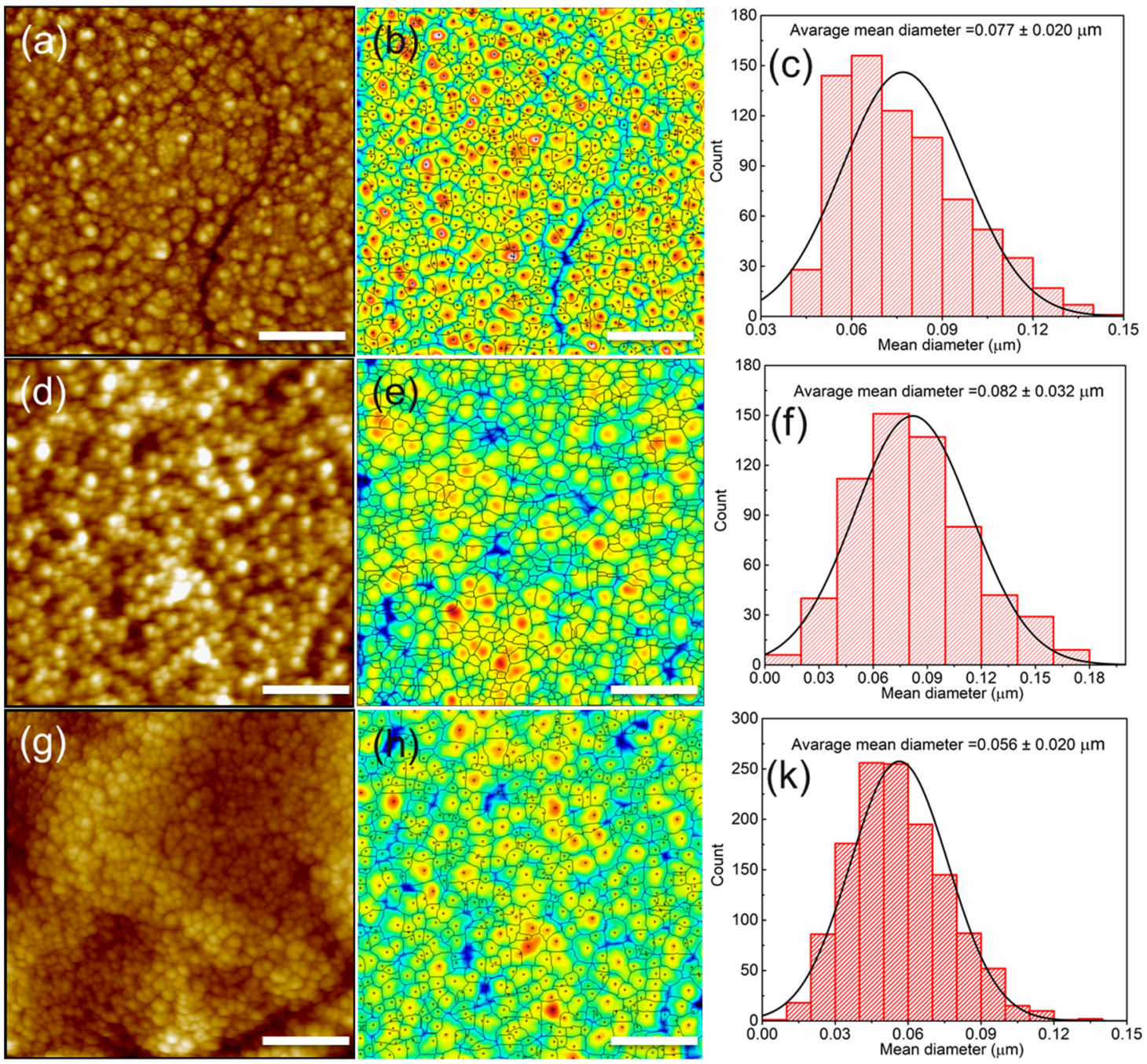

Figure 2. AFM topography, particle segmentation images, and grain-diameter histogram extracted from the watershed detection method of (a-c) AlN film on a $30 \mu \mathrm{m}$ thick Ni foil, (d-f) AlN film on a $12.5 \mu \mathrm{m}$ thick Fe foil, and (g-k) AlN film on a $15 \mu \mathrm{m}$ thick Co foil. Scale bar is $500 \mathrm{~nm}$.

films grown on Fe and Co foils show a sharp interface without delamination. It is also observed that the nanocrystalline grains are embedded in an amorphous phase and that a columnar structure is present. The SAED patterns inserted in Figures 4a and 5 a reveal that AlN films grown on $\mathrm{Fe}$ and $\mathrm{Co}$ foils have a (002) preferred orientation. Among the three samples, AlN films grown on $\mathrm{Ni}$ and Co show better crystallinity compared to the film grown on $\mathrm{Fe}$, as sharp and intense rings are observed.

Transition layers of 30 and $20 \mathrm{~nm}$ are observed in the Fe and Co samples, as shown in Figures $4 c$ and $5 c$, respectively. These layers are partially amorphous, consisting of $\mathrm{Al}_{x} \mathrm{O}_{y}$, $\mathrm{AlO}_{x} \mathrm{~N}_{y}$, and $\mathrm{AlN}$ layers. These are further confirmed by chemical analyses (EEL spectra shown in Figures $4 \mathrm{e}-\mathrm{h}$ and $5 \mathrm{e}-\mathrm{h})$. Otherwise, the FFT shows strong diffuse amorphous rings (Figures $4 \mathrm{c}$ and $5 \mathrm{c}$ ). As the films grows, its crystallinity increases with a (002) preferred orientation (Figures $4 \mathrm{~d}$ and $5 \mathrm{~d})$. It can be noted that an iron oxide layer of $10 \mathrm{~nm}$ is observed in STEM-EELS (Figure $4 \mathrm{e}-\mathrm{h}$ ), which may be due to iron foil processing. Furthermore, no significant diffusion of elements through the interface can be detected. The origin of the formation of amorphous $\mathrm{Al}_{x} \mathrm{O}_{y}$ and $\mathrm{AlO}_{x} \mathrm{~N}_{y}$ layers is due to the presence of hydroxyl groups on surface substrates that act as radical groups in the ligand exchange reaction, causing the formation of a transition layer. In addition, the presence of residual water molecules and oxygen gas inside the reaction chamber during the first stages of the PE-ALD process is also a source of oxygen atoms participating in the chemical reaction of the film deposition. During the process, complete saturation of the reactor chamber with the nitrogen/argon/hydrogen gases lowers the presence of the water and $\mathrm{O}_{2}$ molecules. Notably, the film microstructure grown on $\mathrm{Ni}$ and $\mathrm{Fe}$ is quite different from the film grown on Co. The continuous columnar structure is observed in $\mathrm{AlN} / \mathrm{Ni}$ and $\mathrm{AlN} / \mathrm{Fe}$ samples, as shown in Figures S3 and S4. It is still obtained in the AlN/Co sample; however, "twin boundaries" are also present (Figure S5). The twin boundaries are formed due to the misalignment between AlN grains, which originates from the microstructure of the Co substrate, whereas $\mathrm{Ni}$ and Fe foils are constructed by grains with different sizes and different orientations causing a smooth surface. The misalignment of crystalline grains may cause a cancellation among the electrical dipoles in the conformal AlN film, leading to a decrease in the piezoelectric response, as well as magnetoelectric transduction in the AlN/ Co composite. This will be discussed further in the section about the magnetoelectric measurements.

Depth-profile SIMS analysis for the AlN films grown on $\mathrm{Ni}$, $\mathrm{Fe}$, and Co foils was carried out to further study the depth 

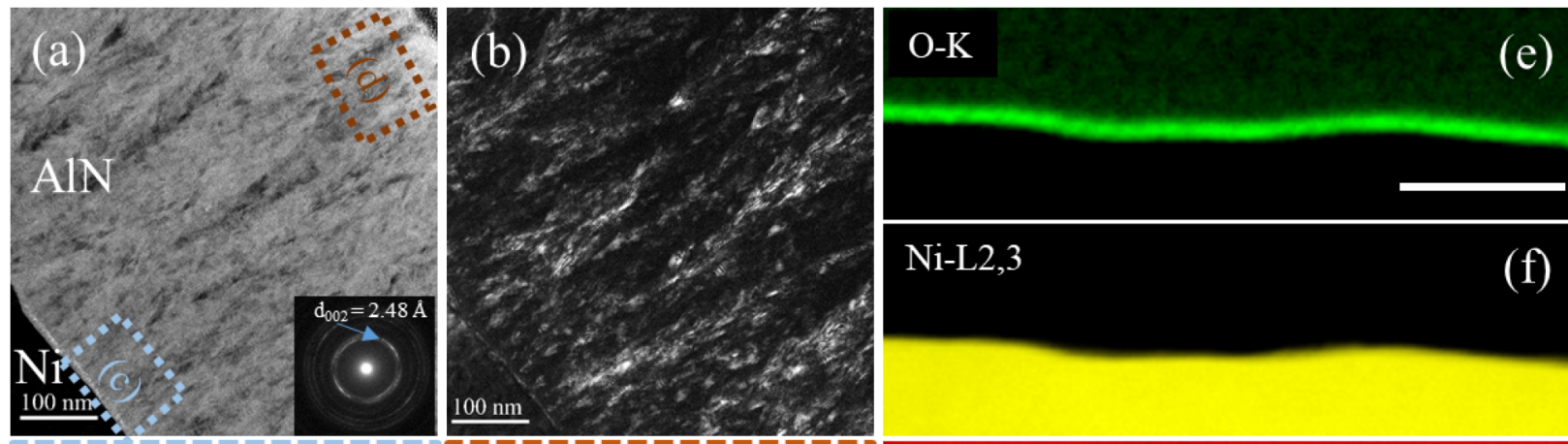

\section{$\mathrm{Ni}-\mathrm{L} 2,3$}

(f)
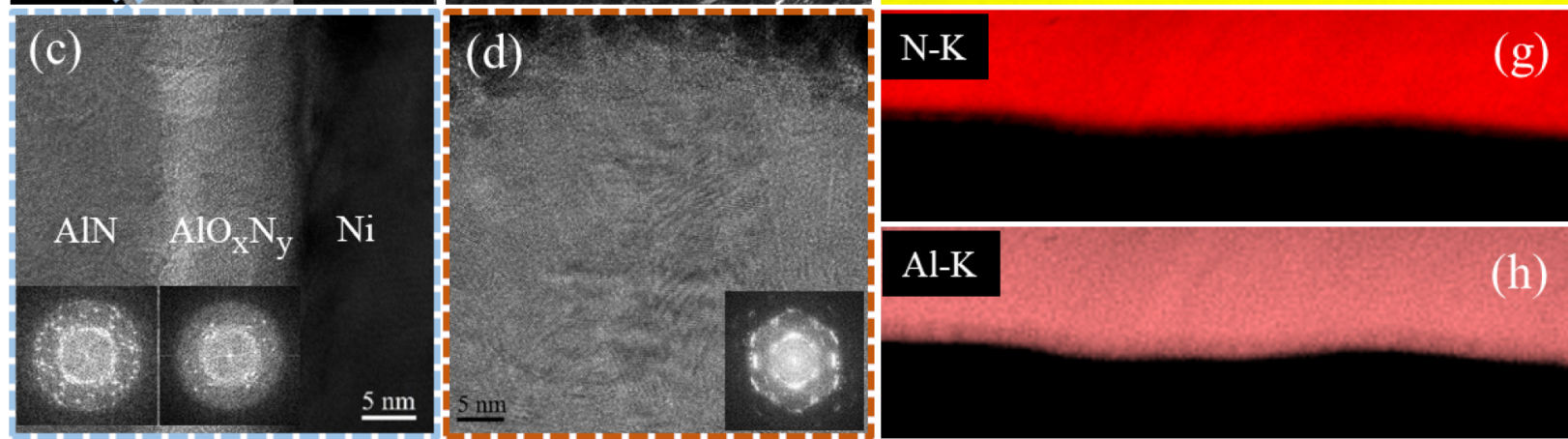

Figure 3. (a) Bright-field (BF) micrograph and inserted SAED pattern of a cross-section of the AlN layer. (b) Dark-field (DF) TEM micrograph of the AlN film on a $30 \mu \mathrm{m}$ thick Ni foil. HR-TEM images and inserted fast-Fourier transform at (c) the interface between AlN and Ni (blue dashed square in a) and (d) the top layer of AlN (brown dashed square in a). (e-h) STEM-EELS mappings for O K, Ni L2,3, N K, and Al K edges, respectively. Scale bar in the STEM-EELS images is $100 \mathrm{~nm}$.
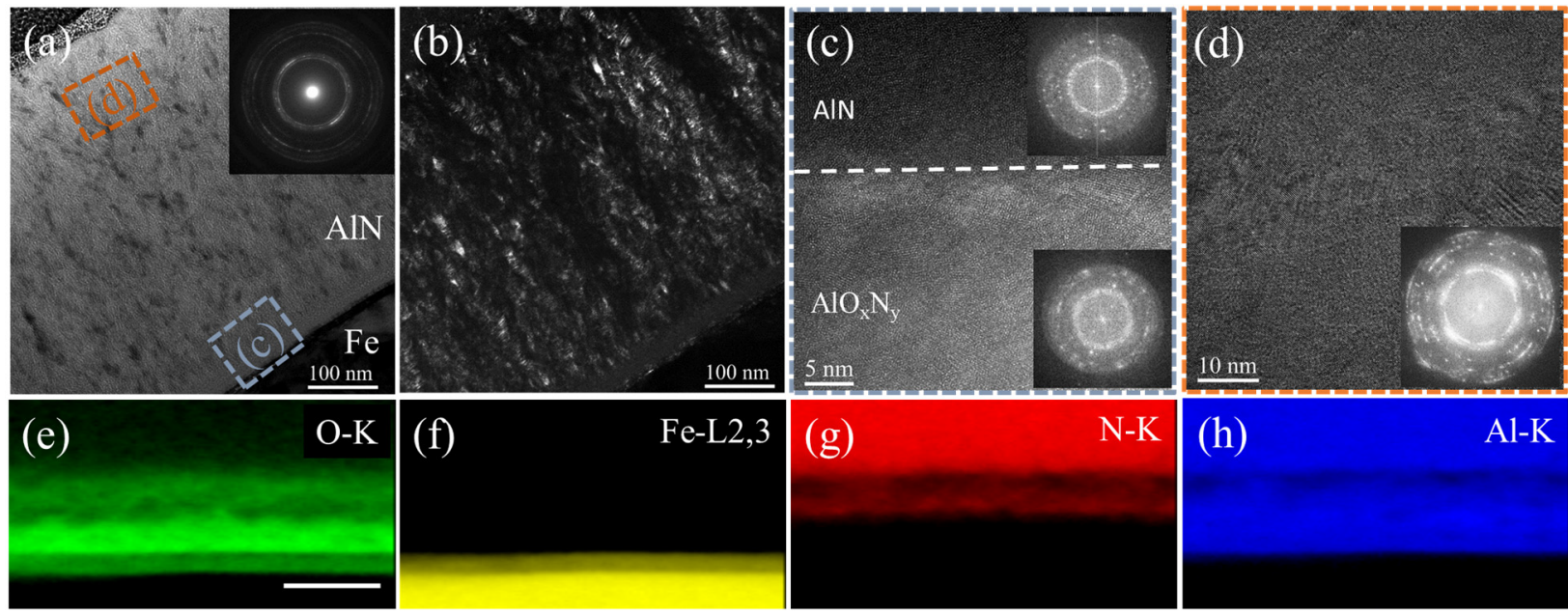

Figure 4. (a) Bright-field (BF) micrograph and inserted SAED pattern of a cross-section of the AlN layer. (b) Dark-field (DF) TEM micrograph of the AlN film on a $12.5 \mu \mathrm{m}$ thick Fe foil. HR-TEM images and inserted fast-Fourier transform at (c) the interface between AlN and Fe (the blue dash square) and (d) the top layer of AlN (brown dashed square). (e-h) STEM-EELS mappings for O K, Fe L2,3, N K, and Al K edges, respectively. Scale bar in the STEM-EELS images is $100 \mathrm{~nm}$.

profile of $\mathrm{Al}$ and $\mathrm{N}$ as well as defect levels such as $\mathrm{O}, \mathrm{C}$, and $\mathrm{H}$, as shown in Figure 6. The distributions of $\mathrm{Al}$ and $\mathrm{N}$ were found to be constant though the whole film thickness for all three samples. The $\mathrm{O}, \mathrm{C}$, and $\mathrm{H}$ impurities are clearly present. Due to the lack of a standard sample, the atomic percentage cannot be determined. However, the level of impurity can be compared. The film grown on a Co foil contains the highest $\mathrm{C}$ contamination, whereas the film grown on a Ni foil contains the highest $\mathrm{O}$ contamination. In addition, the previous study ${ }^{47}$ reported that the atomic percentages of $\mathrm{C}$ and $\mathrm{O}$ in the bulk were about 2 and 7.5 atom $\%$.
It is noted that the presence of $\mathrm{H}$ was clearly observed through the whole film by D-SIMS. The remarkable presence of oxygen inside the films strongly affects not only the crystal quality but also the piezoelectric response of the AlN film as demonstrated by Akiyama et al. ${ }^{54}$ and Vergara et al. ${ }^{55}$ Vergara and co-workers ${ }^{55}$ showed that the electromechanical coupling factor was drastically decreased on increasing the oxygen concentration. Akiyama et al. ${ }^{54}$ revealed a significant increase of the full width half maximum of the (002) diffraction peak and a remarkable decrease of the piezoelectric response as the oxygen concentration increased. That could explain why a low piezoelectric coefficient $e_{31, \mathrm{f}}$ of $0.37 \mathrm{C} \cdot \mathrm{m}^{-2}$ was obtained in our 

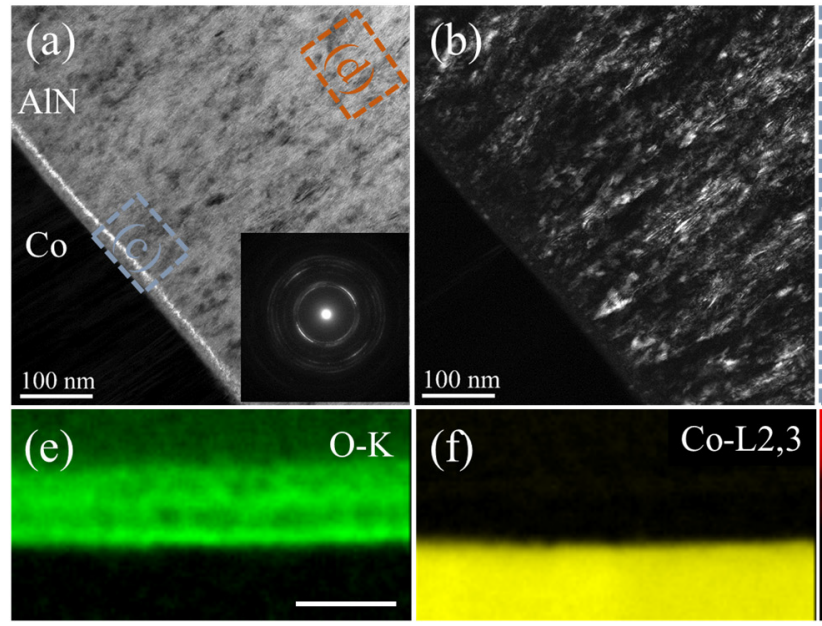
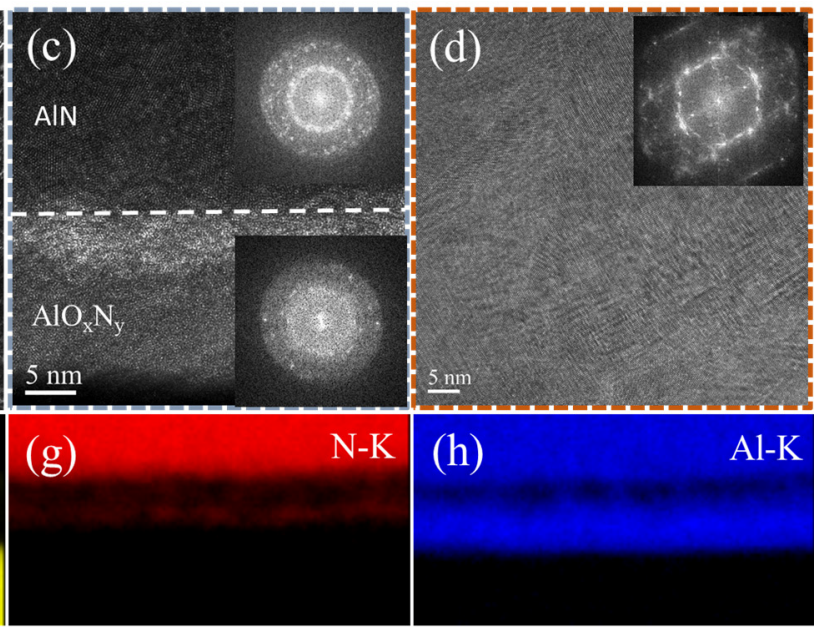

Figure 5. (a) Bright-field (BF) micrograph and inserted SAED pattern of a cross-section of the AlN layer. (b) Dark-field (DF) TEM micrograph of the AlN film on a $15 \mu \mathrm{m}$ thick Co foil. HR-TEM images and inserted fast-Fourier transform at (c) the interface between AlN and Co (blue dashed square) and (d) the top layer of AlN (orange dashed square). (e-h) STEM-EELS mappings for O K, Co L2,3, N K, and Al K edges, respectively. Scale bar in the STEM-EELS images is $100 \mathrm{~nm}$.

films. ${ }^{47}$ However, those impurity levels are comparable to those found in the literature. ${ }^{56,57}$ Minimization of those impurities is really challenging in chemical vapor deposition due to the presence of residual moisture in the reactor chamber and the carrier gases.

The tape test was carried out to evaluate the adhesion of the AlN films on the magnetostrictive foils. Figures S6, S7, and S8 show the results of the tape test of the AlN/Ni, AlN/Fe, and AlN/Co samples, respectively. The tests on the three samples were classified as class 5 according to the ASTM D3359 standard, ${ }^{49}$ i.e., the edges of the cuts are completely smooth; none of the squares of the lattice are detached. The tape test verified an excellent adhesion of the AlN films on the $\mathrm{Ni}, \mathrm{Fe}$, and Co foils.

Figure $7 \mathrm{a}$ shows the magnetization measurement data of a pristine $\mathrm{Ni}$ foil and $\mathrm{Al} / \mathrm{Ni}$ composites. All of the $\mathrm{Al} / \mathrm{Ni}$ samples show ferromagnetic behavior with typical symmetric magnetic hysteresis loops. It should be noted that a pure AlN thin film is diamagnetic in nature. Therefore, the ferromagnetic characteristics of the AlN/Ni samples stem from the Ni foils. It can be seen that the magnetic hysteresis loops are the same among the $\mathrm{Al} / \mathrm{Ni}$ composites regardless of the thickness of the $\mathrm{Ni}$ foils. The saturation magnetization of a pure $\mathrm{Ni}$ foil and $\mathrm{Al} / \mathrm{Ni}$ composite is approximately $56 \mathrm{emu} / \mathrm{g}$, which is quite close to the expected value for a bulk $\mathrm{Ni}$ of $58.6 \mathrm{emu} / \mathrm{g}$.

Figure $7 \mathrm{~b}$ illustrates the $\mathrm{ME}$ coefficient $\left(\alpha_{\mathrm{ME}}\right)$ as a function of a dc-biased magnetic field $\left(H_{\mathrm{dc}}\right)$ for AlN/Ni thin-film composites, measured at an off-resonance frequency of $46 \mathrm{~Hz}$. The asymmetry of the ME coefficient curve is related to the asymmetry of the magnetostriction nature of nickel. ${ }^{58}$ When a dc magnetic field superimposed with a weak ac magnetic field is applied parallel to the plane of the AlN/Ni samples, spins present in nickel are aligned to the direction of the applied magnetic field. The alignment of spins causes the magnetic domain movements and surface modulations. This magnetic domain switching results in magnetoelastic deformation, which is then mechanically transferred to the AlN film via the interface, subsequently generating charges and an electrical field in the piezoelectric film. For all measurements, $\alpha_{\mathrm{ME}}$ exhibited a typical $H_{\mathrm{dc}}$ dependence showing the hysteresis behavior during the $H_{\mathrm{dc}}$ sweep and a sign change with respect to the reversal of the $H_{\mathrm{dc}}$ direction. The $H_{\mathrm{dc}}$ dependence of $\alpha_{\mathrm{ME}}$ is correlated to the first derivative of the magnetostriction or the piezomagnetic coefficient, $\mathrm{d} \lambda / \mathrm{d} H$, where $\lambda$ is the magnetostriction and $H$ is the applied magnetic field. ${ }^{58}$ In general, the $\alpha_{\mathrm{ME}}$ increases as $H_{\mathrm{dc}}$ increases, reaching its maximum value at a particular $H_{\mathrm{dc}}$ value at which the maximum piezomagnetic coefficient is achieved, after which it drastically decreases as $H_{\mathrm{dc}}$ continues to increase. Interestingly, in our AlN/Ni thin-film composites, a maximum $\alpha_{\mathrm{ME}}$ was obtained at a zero bias field $\left(H_{\mathrm{dc}}=0 \mathrm{Oe}\right)$. The nearly maximum $\alpha_{\mathrm{ME}}$ at zero dc magnetic field has also been reported in other composites such as Ni/PMT $\left(0.8\left[\mathrm{~Pb}\left(\mathrm{Zr}_{0.52} \mathrm{Ti}_{0.48} \mathrm{O}_{3}\right]+\right.\right.$ $\left.0.2\left[\mathrm{~Pb}\left(\mathrm{Zn}_{1 / 3} \mathrm{Nd}_{2 / 3}\right) \mathrm{O}_{3}\right]+2 \mathrm{~mol} \% \mathrm{MnO}_{2}\right),{ }^{59} \mathrm{Ni} / \mathrm{MFC}$ (macrofiber composite), ${ }^{60}$ and Ni/SFC (single-crystal fiber composite). ${ }^{41,61}$ The intrinsic self-biased $\alpha_{\mathrm{ME}}$ is attributed to the hysteretic magnetic nature of the Ni foil. Zhou et al. ${ }^{59}$ demonstrated that $\mathrm{Ni}$ foil possesses macrosized domains with a long-range ordering, which resulted in the larger coercive field. When the magnetic domains are reoriented, a higher magnetic field is required to achieve the random state, causing larger hysteresis in the magnetization curve. In the present study, the maximum $\alpha_{\mathrm{ME}}$ values were about $3.3,2.8$, and $3.1 \mathrm{~V} \cdot \mathrm{cm}^{-1} \cdot \mathrm{Oe}^{-1}$ for AlN/Ni thin-film composites with a Ni foil thickness of 7.5, 15 , and $30 \mu \mathrm{m}$, respectively. Greve et al. ${ }^{62}$ reported a giant ME coefficient of $3.1 \mathrm{~V} \cdot \mathrm{cm}^{-1} \cdot \mathrm{Oe}^{-1}$ measured at an off-resonance frequency of $100 \mathrm{~Hz}$ in an AlN/Metglas thin-film composite coated in a free-standing cantilever. The AlN layer used is 1.8 $\mu \mathrm{m}$ thick with an $e_{31, \mathrm{f}}$ value of $1.2 \mathrm{C} \cdot \mathrm{m}^{-2}$, which is approximately three times thicker than our AlN thin film with a piezoelectric coefficient $e_{31, \mathrm{f}}$ of $0.37 \mathrm{C} \cdot \mathrm{m}^{-2}{ }^{47}$ Moreover, the piezomagnetic coefficient of Metglas of about $1.4 \mathrm{ppm} / \mathrm{Oe}$ is also almost three times higher than that of $\mathrm{Ni}$ with a value of $0.3 \mathrm{ppm} / \mathrm{Oe} .^{63}$ Therefore, the high $\alpha_{\mathrm{ME}}$ obtained in our AlN/ $\mathrm{Ni}$ thin-film composites can be attributed to an excellent interface quality between the AlN thin film and the $\mathrm{Ni}$ foils produced by a highly conformal coating by PE-ALD and a lowtemperature process limiting atomic interdiffusion, microcracks, and delamination due to the different coefficients of thermal expansion of the two layers.

Figure $8 \mathrm{a}$ and $8 \mathrm{~b}$ shows the magnetization and magnetoelectric measurements for the AlN/Fe and AlN/Co samples. 

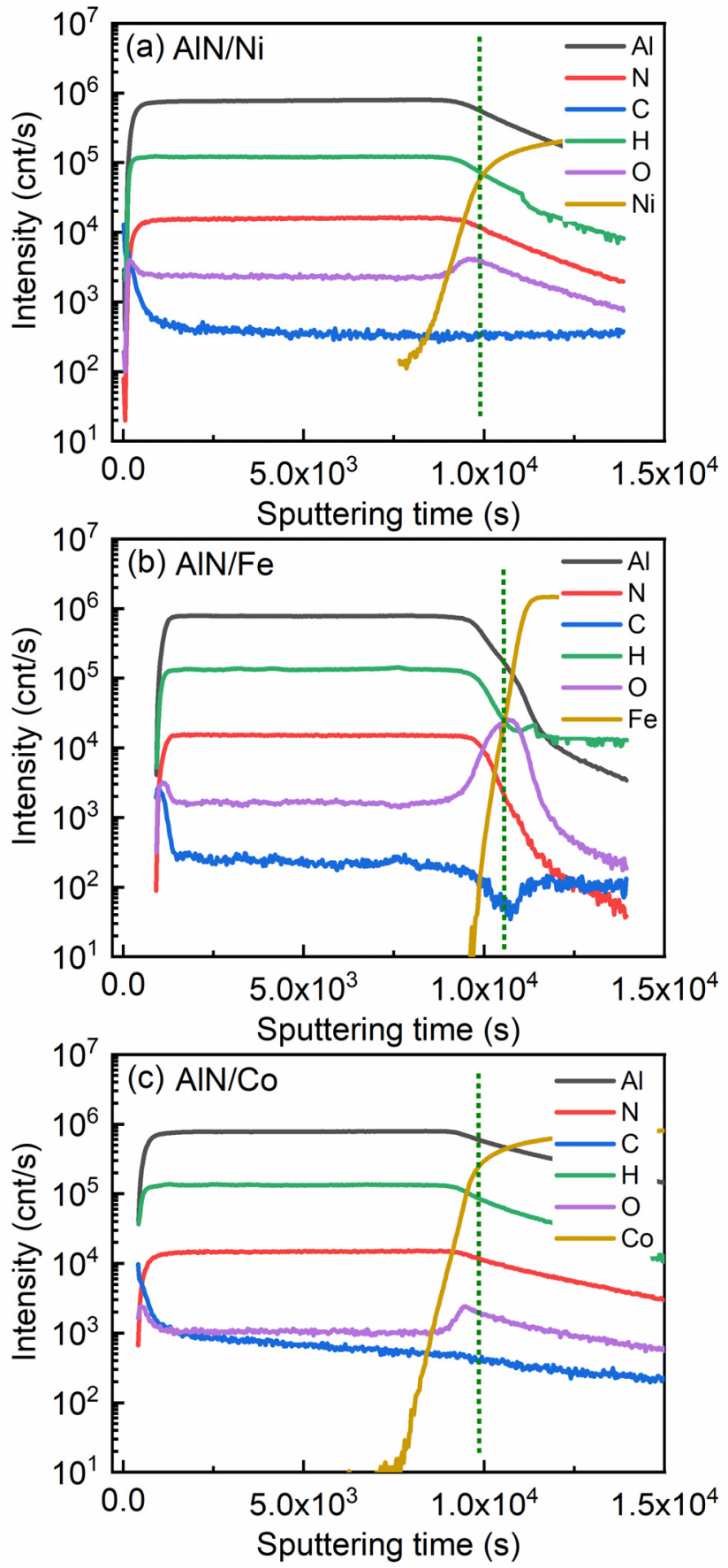

Figure 6. D-SIMS depth-profile analysis for the AlN films grown on (a) $15 \mu \mathrm{m}$ thick Ni, (b) $12.5 \mu \mathrm{m}$ thick Fe, and (c) $15 \mu \mathrm{m}$ thick Co foils. Dark green dashed lines are used to indicate the transition between the films (left) and the foils (right).

The saturation magnetization is about 205 and $160 \mathrm{emu} / \mathrm{g}$ for $\mathrm{AlN} / \mathrm{Fe}$ and AlN/Co, as shown in Figure 8a. The maximum magnetoelectric coefficient, $\alpha_{\mathrm{ME}}$, of the $\mathrm{AlN} / \mathrm{Fe}$ and $\mathrm{Al} / \mathrm{Co}$ composites (Figure $8 \mathrm{~b}$ ) was measured as being approximately 0.32 and $0.12 \mathrm{~V} \cdot \mathrm{cm}^{-1} \cdot \mathrm{Oe}^{-1}$ at $46 \mathrm{~Hz}$ with a bias magnetic field $\left(H_{\mathrm{dc}}\right)$ of 6 and $200 \mathrm{Oe}$, respectively. Compared to the AlN film grown on $\mathrm{Ni}$ foils, the magnetoelectric response in $\mathrm{Al} / \mathrm{Fe}$ and $\mathrm{Al} / \mathrm{Co}$ samples is about 1 order of magnitude weaker. This can be attributed to a stronger magnetostrictive effect in $\mathrm{Ni}$ compared to $\mathrm{Fe}$ and Co. Klokholm et al. reported magneto-

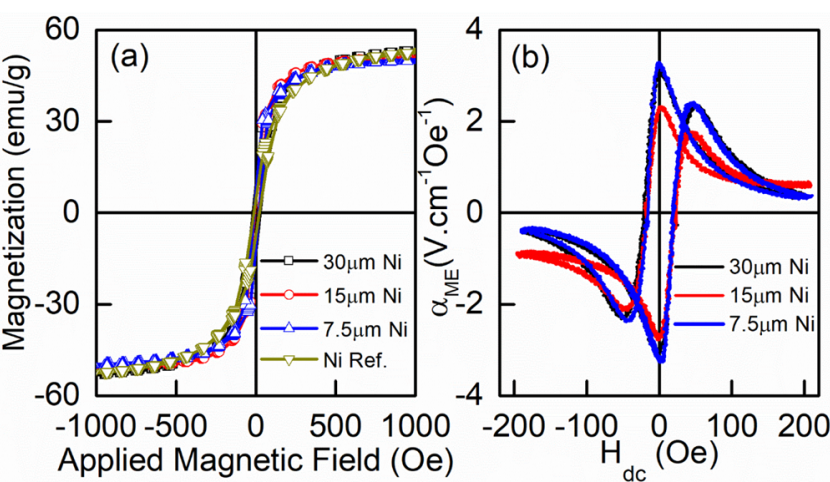

Figure 7. (a) Magnetization measurements of nickel samples with thicknesses of $7.5,15$, and $30 \mu \mathrm{m}$ with a $550 \mathrm{~nm}$ thick AlN film deposited on top and a pristine $100 \mu \mathrm{m}$ thick $\mathrm{Ni}$ foil. (b) Magnetoelectric coefficient $\left(\alpha_{\mathrm{ME}}\right)$ measurements, performed at a constant ac magnetic field amplitude of 8.5 Oe and a frequency of 46 $\mathrm{Hz}$, of AlN/Ni composites. Magnetic dc bias forward $\left(-\mathrm{H}_{\mathrm{dc}} \rightarrow 0 \rightarrow\right.$ $\left.+\mathrm{H}_{\mathrm{dc}}\right)$ and backward $\left(+\mathrm{H}_{\mathrm{dc}} \rightarrow 0 \rightarrow-\mathrm{H}_{\mathrm{dc}}\right)$ ME measurements were both performed.

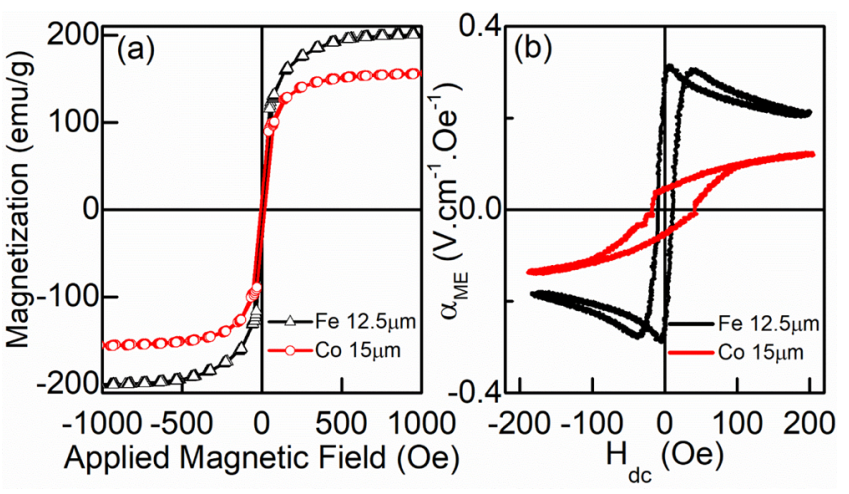

Figure 8. (a) Magnetization measurements of $12.5 \mu \mathrm{m}$ thick Fe and $15 \mu \mathrm{m}$ thick Co samples with a $550 \mathrm{~nm}$ thick AlN film deposited on top. (b) Magnetoelectric coefficient $\left(\alpha_{\mathrm{ME}}\right)$ measurements, performed at a constant ac magnetic field amplitude of $8.5 \mathrm{Oe}$ and a frequency of $46 \mathrm{~Hz}$, of AlN/Fe and AlN/Co composites. Magnetic dc bias forward $\left(-\mathrm{H}_{\mathrm{dc}} \rightarrow 0 \rightarrow+\mathrm{H}_{\mathrm{dc}}\right)$ and backward $\left(+\mathrm{H}_{\mathrm{dc}} \rightarrow 0 \rightarrow-\mathrm{H}_{\mathrm{dc}}\right)$ ME measurements were both performed.

strictive hysteresis loop measurements on nickel, iron, and cobalt in the shape of thin polycrystalline films. ${ }^{58}$

The authors highlighted the maximum magnetostriction coefficients of $\lambda=-6,-3.5$, and $-11.2 \mathrm{ppm}$ for iron, cobalt, and nickel, respectively. The same authors experienced a large variation of this saturation magnetostriction coefficient for cobalt, which is quite sensitive to the deposition process (sputtering and thermal evaporation in this study) and postannealing eliminating the fcc phase with an unusual change in the magnetostrictive behavior. This is also confirmed by the trend we observed about the maximum magnetoelectric coefficient values we measured for these three metals. In our case, we could explain the lowest $\alpha_{\mathrm{ME}}$ coefficient in the AlN/ Co composite as due to the misalignment of the (002)oriented columnar grains of the piezoelectric AlN film conformally grown on a Co surface, as revealed by the HRTEM micrographs in Figure S5 (Supporting Information).

For potential applications of such ME composites in energy harvesters, output voltage and power density as a function of load resistance were determined on the AlN/Ni sample, as 
illustrated in Figure 9. It is interesting to point out that a maximum power density of approximately $75 \mathrm{nW} / \mathrm{cm}^{3}$ on a

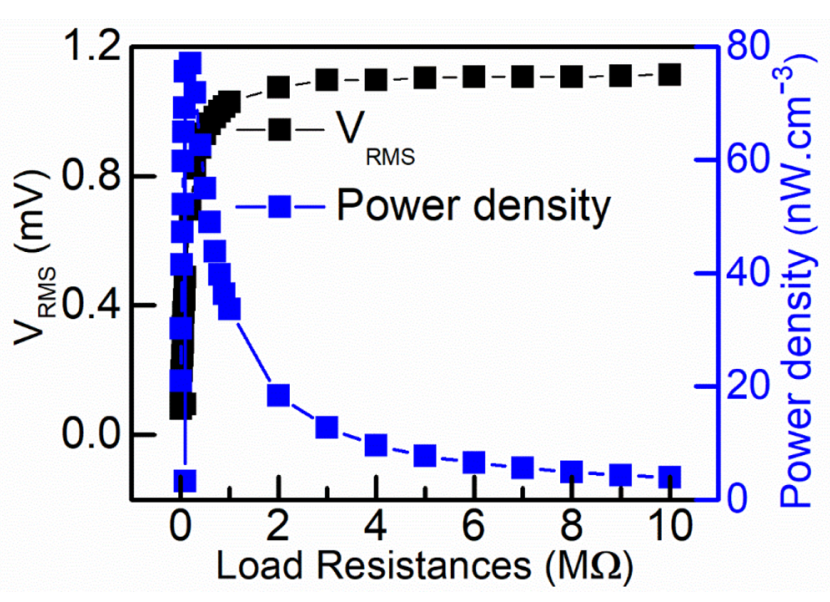

Figure 9. Output voltage and power density as a function of load resistance measured for $\mathrm{AlN} / \mathrm{Ni}$ composite sample under an ac magnetic field intensity of $8.5 \mathrm{Oe}$ at out-of-resonance frequency of 46 $\mathrm{Hz}$. No dc magnetic field bias was applied.

load resistance of $200 \mathrm{k} \Omega$ was obtained. Although a strong ME effect was achieved in PZT/Ni, ${ }^{29}$ PZT- $\mathrm{NiFe}_{2} \mathrm{O}_{4}-\mathrm{PZT},{ }^{64} \mathrm{PZT}$ on amorphous Metglas foil, ${ }^{65}$ and $\left(\mathrm{Fe}_{90} \mathrm{Co}_{10}\right)_{78} \mathrm{Si}_{12} \mathrm{~B}_{10} / \mathrm{AlN}^{62}$ thin-film composites, an output power has not been reported. Recently, Ghosh et al. ${ }^{66}$ reported a peak output power density of $50 \mathrm{nW} / \mathrm{cm}^{3}$ in $0-3 \mathrm{ME}$ films with a thickness of $9 \mu \mathrm{m}$ made of $\mathrm{NiFe}_{2} \mathrm{O}_{4}$ nanoparticles added to $\mathrm{P}(\mathrm{VDF}-\mathrm{TrFE})$. It has been reported that the ME coefficient as well as the power density can be further improved using the resonance structures. ${ }^{41,61,62}$ It, therefore, will be a future approach by which to upgrade the performance of our composites.

\section{CONCLUSION}

Thin-film magnetoelectric composites made of piezoelectric AlN thin films and magnetostrictive foils were synthesized with a detailed analysis of the interfaces in order to optimize the mechanical energy transfer. The AlN film deposited using plasma-enhanced atomic layer deposition (PE-ALD) at a low temperature of $250{ }^{\circ} \mathrm{C}$ exhibited a preferred (002) orientation and a usable piezoelectric response with a direct piezoelectric coefficient $e_{31, \mathrm{f}}$ of $0.37 \mathrm{C} / \mathrm{m}^{2}$. The film crystal properties and the interface between the films and the foils were carefully investigated by high-resolution transmission electron microscopy. It was found that a transition layer of amorphous $\mathrm{Al}_{x} \mathrm{O}_{y} /$ $\mathrm{AlO}_{x} \mathrm{~N}_{y}$ was formed between the films and the foils. The thicknesses of transition layers were 10, 30, and $20 \mathrm{~nm}$ for the films grown on $\mathrm{Ni}, \mathrm{Fe}$, and $\mathrm{Co}$. The evolution of the crystallinity of the AlN film was studied, showing that the film was amorphous at the interface and significantly improved during the ALD growth. The interface between the AlN films and the foils was clear and continuous. A strong self-biased magnetoelectric coefficient was achieved in AlN/Ni composites, namely, the maximum magnetoelectric coefficients of the AlN/Ni composites with $\mathrm{Ni}$ foil thicknesses of 7.5, 15, and 30 $\mu \mathrm{m}$ were $3.3,2.8$, and $3.1 \mathrm{~V} \cdot \mathrm{cm}^{-1} \cdot \mathrm{Oe}^{-1}$ measured at an offresonance frequency of $46 \mathrm{~Hz}$ and at a zero-bias dc magnetic field. Moreover, the magnetoelectric effect was studied in composites made of $550 \mathrm{~nm}$ thick films grown on $12.5 \mu \mathrm{m}$ thick $\mathrm{Fe}$ and $15 \mu \mathrm{m}$ thick Co foils. The maximum magnetoelectric coefficient of $\mathrm{AlN} / \mathrm{Fe}$ and $\mathrm{Al} / \mathrm{Co}$ composites was approximately 0.32 and $0.12 \mathrm{~V} \cdot \mathrm{cm}^{-1} \cdot \mathrm{Oe}^{-1}$ characterized at $46 \mathrm{~Hz}$ with bias fields $\left(H_{\mathrm{dc}}\right)$ of 6 and 200 Oe. A maximum power density of $75 \mathrm{nW} / \mathrm{cm}^{3}$ was produced on a load resistance of $200 \mathrm{k} \Omega$. A strong magnetoelectric coupling obtained in $\mathrm{AlN} / \mathrm{Ni}$ composites, compared to $\mathrm{Fe}$ and $\mathrm{Co}$ samples, can be attributed to the higher magnetostrictive response of nickel and an excellent interface quality between the AlN film and the Ni surface, which is due to a highly conformal coating profile and a low-temperature process. With these advantages, plasma-enhanced atomic layer deposition opens up a simple and efficient pathway to design a novel material compatible with cleanroom facilities for MEMS energy harvesters and electromagnetic sensors in which the interface effects, such as morphologic roughness, microcracks, delamination, and interdiffusion, can be alleviated.

\section{ASSOCIATED CONTENT}

\section{Supporting Information}

The Supporting Information is available free of charge at https://pubs.acs.org/doi/10.1021/acsami.1c08399.

Additional information with complementary data concerning the procedure of the tape test and the results of the tape test; and cross-sectional STEM BF and STEM-HAADF micrographs of $\mathrm{AlN} / \mathrm{Ni}, \mathrm{AlN} / \mathrm{Fe}$, and AlN/Co (PDF)

\section{AUTHOR INFORMATION}

\section{Corresponding Author}

Jérôme Polesel-Maris - Materials Research and Technology Department, Luxembourg Institute of Science and Technology, L-4422 Belvaux, Luxembourg; orcid.org/ 0000-0003-0457-619X; Email: jerome.polesel@list.lu

\section{Authors}

Tai Nguyen - Materials Research and Technology Department, Luxembourg Institute of Science and Technology, L-4422 Belvaux, Luxembourg; Department of Physics and Materials Science, University of Luxembourg, L1511 Luxembourg, Luxembourg

Yves Fleming - Materials Research and Technology Department, Luxembourg Institute of Science and Technology, L-4422 Belvaux, Luxembourg

Philipp Bender - Department of Physics and Materials Science, University of Luxembourg, L-1511 Luxembourg, Luxembourg; Present Address: P.B.: Heinz Maier-Leibnitz Zentrum (MLZ), Technische Universität München, D85748 Garching, Germany.; (i) orcid.org/0000-00022492-3956

Patrick Grysan - Materials Research and Technology Department, Luxembourg Institute of Science and Technology, L-4422 Belvaux, Luxembourg

Nathalie Valle - Materials Research and Technology Department, Luxembourg Institute of Science and Technology, L-4422 Belvaux, Luxembourg

Brahime El Adib - Materials Research and Technology Department, Luxembourg Institute of Science and Technology, L-4422 Belvaux, Luxembourg

Noureddine Adjeroud - Materials Research and Technology Department, Luxembourg Institute of Science and Technology, L-4422 Belvaux, Luxembourg 
Didier Arl - Materials Research and Technology Department, Luxembourg Institute of Science and Technology, L-4422 Belvaux, Luxembourg

Mélanie Emo - Université de Lorraine, CNRS, Institut Jean Lamour, UMR 7198, F-54000 Nancy, France

Jaafar Ghanbaja - Université de Lorraine, CNRS, Institut Jean Lamour, UMR 7198, F-54000 Nancy, France

Andreas Michels - Department of Physics and Materials Science, University of Luxembourg, L-1511 Luxembourg, Luxembourg

Complete contact information is available at: https://pubs.acs.org/10.1021/acsami.1c08399

\section{Author Contributions}

The manuscript was written with contributions from all authors. All authors have given their approval to the final version of the manuscript.

\section{Author Contributions}

T.N.: Methodology, experiments (ALD processes, characterizations), data acquisition and analysis, manuscript writing of the original draft, review, and editing. Y.F.: XRD experiments and data analysis interpretation, review, and editing. P.B.: VSM measurements and data treatment and analysis. P.G.: AFM measurements and data treatment and analysis. N.V.: SIMS analysis. B.E.A.: SIMS analysis. N.A.: Methodology, experiments (ALD processes). D.A.: Electron microscopy analysis and data interpretation. M.E.: HR-TEM and STEM sample preparation and analysis. J.G.: HR-TEM and STEM data analysis, image treatment, manuscript reviewing and editing. A.M.: VSM measurements, data treatment and analysis, manuscript reviewing and editing. J.P.-M.: Project manager, supervisor, ALD and ME experiments, ME bench realization, data analysis, funding acquisition, manuscript writing, review. and editing.

\section{Notes}

The authors declare no competing financial interest.

\section{ACKNOWLEDGMENTS}

The authors acknowledge Dr. Sebastjan Glinsek for $e_{31 f}$ measurements and Dr. Torsten Granzow for fruitful discussions on the magnetoelectric measurements. We gratefully acknowledge the financial support provided by the FNR in the framework of the FNR PRIDE MASSENA 15/10935404/ MASSENA programme and for the CORE grant SANS4NCC (C17/MS/11661571).

\section{REFERENCES}

(1) Schmid, H. Multi-Ferroic Magnetoelectrics. Ferroelectrics 1994, 162, 317-338.

(2) Ramesh, R.; Spaldin, N. A. Multiferroics: Progress and Prospects in Thin Films. Nat. Mater. 2007, 6, 21-29.

(3) Wang, K. F.; Liu, J. M.; Ren, Z. F. Multiferroicity: The Coupling between Magnetic and Polarization Orders. Adv. Phys. 2009, 58, 321448.

(4) Dong, S.; Liu, J. M.; Cheong, S. W.; Ren, Z. Multiferroic Materials and Magnetoelectric Physics: Symmetry, Entanglement, Excitation, and Topology. Adv. Phys. 2015, 64, 519-626.

(5) Fiebig, M.; Lottermoser, T.; Meier, D.; Trassin, M. The Evolution of Multiferroics. Nat. Rev. Mater. 2016, 1, No. 16046.

(6) Kimura, T.; Goto, T.; Shintani, H.; Ishizaka, K.; Arima, T.; Tokura, Y. Magnetic Control of Ferroelectric Polarization. Nature 2003, 426, 55-58.
(7) Astrov, D. N. Magnetoelectric Effect in Chromium Oxide. J. Exp. Theor. Phys. 1961, 40, 1035-1041.

(8) Catalan, G.; Scott, J. F. Physics and Applications of Bismuth Ferrite. Adv. Mater. 2009, 21, 2463-2485.

(9) Khomskii, D. Classifying Multiferroics: Mechanisms and Effects. Physics 2009, 2, No. 20.

(10) Ikeda, N.; Ohsumi, H.; Ohwada, K.; Ishii, K.; Inami, T.; Kakurai, K.; Murakami, Y.; Yoshii, K.; Mori, S.; Horibe, Y.; Kitô, H. Ferroelectricity from Iron Valence Ordering in the Charge-Frustrated System $\mathrm{LuFe}_{2} \mathrm{O}_{4}$. Nature 2005, 436, 1136-1138.

(11) Van Den Brink, J.; Khomskii, D. I. Multiferroicity Due to Charge Ordering. J. Phys.: Condens. Matter 2008, 20, No. 434217.

(12) De Groot, J.; Mueller, T.; Rosenberg, R. A.; Keavney, D. J.; Islam, Z.; Kim, J. W.; Angst, M. Charge Order in $\mathrm{LuFe}_{2} \mathrm{O}_{4}$ : An Unlikely Route to Ferroelectricity. Phys. Rev. Lett. 2012, 108, No. 187601.

(13) Van Aken, B. B.; Palstra, T. T. M.; Filippetti, A.; Spaldin, N. A. The Origin of Ferroelectricity in Magnetoelectric $\mathrm{YMnO}_{3}$. Nat. Mater. 2004, 3, 164-170.

(14) Lilienblum, M.; Lottermoser, T.; Manz, S.; Selbach, S. M.; Cano, A.; Fiebig, M. Ferroelectricity in the Multiferroic Hexagonal Manganites. Nat. Phys. 2015, 11, 1070-1073.

(15) Kimura, T. Spiral Magnets as Magnetoelectrics. Annu. Rev. Mater. Res. 2007, 37, 387-413.

(16) Tokura, Y.; Seki, S. Multiferroics with Spiral Spin Orders. Adv. Mater. 2010, 22, 1554-1565.

(17) Cheong, S. W.; Mostovoy, M. Multiferroics: A Magnetic Twist for Ferroelectricity. Nat. Mater. 2007, 6, 13-20.

(18) Tokura, Y.; Seki, S.; Nagaosa, N. Multiferroics of Spin Origin. Rep. Prog. Phys. 2014, 77, No. 076501.

(19) Ma, J.; Hu, J.; Li, Z.; Nan, C. W. Recent Progress in Multiferroic Magnetoelectric Composites: From Bulk to Thin Films. Adv. Mater. 2011, 23, 1062-1087.

(20) Wang, Y.; Hu, J.; Lin, Y.; Nan, C. W. Multiferroic Magnetoelectric Composite Nanostructures. NPG Asia Mater. 2010, 2, 61-68.

(21) Sallagoity, D.; Elissalde, C.; Majimel, J.; Maglione, M.; Antohe, V. A.; Abreu Araujo, F.; Pereira De Sá, P. M.; Basov, S.; Piraux, L. Synthesis of Dense Arrays of Multiferroic $\mathrm{CoFe}_{2} \mathrm{O}_{4}-\mathrm{PbZr}_{0.52} \mathrm{Ti}_{0.48} \mathrm{O}_{3}$ Core/Shell Nanocables. RSC Adv. 2016, 6, 106716-106722.

(22) Liu, M.; Obi, O.; Lou, J.; Stoute, S.; Cai, Z.; Ziemer, K.; Sun, N. X. Strong Magnetoelectric Coupling in Ferrite/Ferroelectric Multiferroic Heterostructures Derived by Low Temperature Spin-Spray Deposition. J. Phys. D: Appl. Phys. 2009, 42, No. 045007.

(23) Tang, Y.; Wang, R.; Zhang, Y.; Xiao, B.; Li, S.; Du, P. Magnetoelectric Coupling Tailored by the Orientation of the Nanocrystals in Only One Component in Percolative Multiferroic Composites. RSC Adv. 2019, 9, 20345-20355.

(24) El-Ghazaly, A.; Evans, J. T.; Sato, N.; Montross, N.; Ohldag, H.; White, R. M.; Wang, S. X. Electrically Tunable Integrated Thin-Film Magnetoelectric Resonators. Adv. Mater. Technol. 2017, 2, No. 1700062

(25) Zhou, P.; Liang, K.; Liu, Y.; Zheng, Z.; Zhang, T. Effect of Interface Coupling on Magnetoelectric Response of $\mathrm{Pb}\left(\mathrm{Zr}_{0.52} \mathrm{Ti}_{0.48}\right)$ $\mathrm{O}_{3} / \mathrm{La}_{0.67} \mathrm{Sr}_{0.33} \mathrm{MnO}_{3}$ Thin Film under Different Strain States. Appl. Phys. A: Mater. Sci. Process. 2018, 124, No. 670.

(26) Zhou, P.; Singh, A. V.; Li, Z.; Popov, M.A.; Liu, Y.; Filippov, D.A.; Zhang, T.; Zhang, W.; Shah, P.J.; Howe, B.M.; McConney, M.E.; Srinivasan, G.; Page, M.R.; Gupta, A. Magnetoelectric Interactions in Composites of Ferrite Films on Lattice-Matched Substrates and Ferroelectrics. Phys. Rev. Appl. 2019, 11, No. 054045.

(27) Lorenz, M.; Lazenka, V.; Schwinkendorf, P.; Bern, F.; Ziese, M.; Modarresi, H.; Volodin, A.; Van Bael, M. J.; Temst, K.; Vantomme, A.; Grundmann, M. Multiferroic $\mathrm{BaTiO}_{3}-\mathrm{BiFeO}_{3}$ Composite Thin Films and Multilayers: Strain Engineering and Magnetoelectric Coupling. J. Phys. D: Appl. Phys. 2014, 47, No. 135303.

(28) Ryu, H.; Murugavel, P.; Lee, J. H.; Chae, S. C.; Noh, T. W.; Oh, Y. S.; Kim, H. J.; Kim, K. H.; Jang, J. H.; Kim, M.; Bae, C.; Park, J. G. 
Magnetoelectric Effects of Nanoparticulate $\mathrm{Pb}\left(\mathrm{Zr}_{0.52} \mathrm{Ti}_{0.48}\right) \mathrm{O}_{3}$ $\mathrm{NiFe}_{2} \mathrm{O}_{4}$ Composite Films. Appl. Phys. Lett. 2006, 89, No. 102907.

(29) Gupta, R.; Tomar, M.; Kumar, A.; Gupta, V. Performance of Magnetoelectric PZT/Ni Multiferroic System for Energy Harvesting Application. Smart Mater. Struct. 2017, 26, No. 035002.

(30) Amorín, H.; Ricote, J.; San-Felipe, I.; Salazar, N.; Del Campo, R.; Romaguera-Barcelay, Y.; Pérez De La Cruz, J.; Ramos, P.; Vila, E.; Castro, A.; Algueró, M. Multilayer Ceramic Magnetoelectric Composites with Tailored Interfaces for Enhanced Response. ACS Appl. Mater. Interfaces 2017, 9 (44), 39094-39104.

(31) Sahoo, S.; Polisetty, S.; Duan, C. G.; Jaswal, S. S.; Tsymbal, E. Y.; Binek, C. Ferroelectric Control of Magnetism in $\mathrm{BaTiO}_{3} / \mathrm{Fe}$ Heterostructures via Interface Strain Coupling. Phys. Rev. B: Condens. Matter Mater. Phys. 2007, 76, No. 092108.

(32) Vaz, C. A. F.; Hoffman, J.; Segal, Y.; Marshall, M. S. J.; Reiner, J. W.; Zhang, Z.; Grober, R. D.; Walker, F. J.; Ahn, C. H. Control of Magnetism in $\mathrm{Pb}\left(\mathrm{Zr}_{0.2} \mathrm{Ti}_{0.8}\right) \mathrm{O}_{3} / \mathrm{La}_{0.8} \mathrm{Sr}_{0.2} \mathrm{MnO}_{3}$ Multiferroic Heterostructures (Invited). J. Appl. Phys. 2011, 109, No. 07D905.

(33) Li, N.; Liu, M.; Zhou, Z.; Sun, N. X.; Murthy, D. V. B.; Srinivasan, G.; Klein, T. M.; Petrov, V. M.; Gupta, A. Electrostatic Tuning of Ferromagnetic Resonance and Magnetoelectric Interactions in Ferrite-Piezoelectric Heterostructures Grown by Chemical Vapor Deposition. Appl. Phys. Lett. 2011, 99, No. 192502.

(34) van den Boomgaard, J.; Born, R. A. J. A Sintered Magnetoelectric Composite Material $\mathrm{BaTiO}_{3}-\mathrm{Ni}(\mathrm{Co}, \mathrm{Mn}) \mathrm{Fe}_{2} \mathrm{O}_{4}$. J. Mater. Sci. 1978, 13, 1538-1548.

(35) Premkumar, S.; Varadharajan, E.; Rath, M.; Mathe, V. L.; Ramachandra Rao, M. S. Microstructural Analysis of Co-Sintered PSLZT-NZFO Layered Magnetoelectric Composite. Ferroelectrics 2017, 516, 60-66.

(36) Zavaliche, F.; Zheng, H.; Mohaddes-Ardabili, L.; Yang, S. Y.; Zhan, Q.; Shafer, P.; Reilly, E.; Chopdekar, R.; Jia, Y.; Wright, P.; Schlom, D. G.; Suzuki, Y.; Ramesh, R. Electric Field-Induced Magnetization Switching in Epitaxial Columnar Nanostructures. Nano Lett. 2005, 5 (9), 1793-1796.

(37) Wan, J. G.; Wang, X. W.; Wu, Y. J.; Zeng, M.; Wang, Y.; Jiang, H.; Zhou, W. Q.; Wang, G. H.; Liu, J. M. Magnetoelectric $\mathrm{CoFe}_{2} \mathrm{O}_{4}$ $\mathrm{Pb}(\mathrm{Zr}, \mathrm{Ti}) \mathrm{O}_{3}$ Composite Thin Films Derived by a Sol-Gel Process. Appl. Phys. Lett. 2005, 86, No. 122501.

(38) Ryu, J.; Priya, S.; Uchino, K.; Kim, H. E. Magnetoelectric Effect in Composites of Magnetostrictive and Piezoelectric Materials. J. Electroceram. 2002, 8, 107-119.

(39) Mori, K.; Wuttig, M. Magnetoelectric Coupling in Terfenol-D/ Polyvinylidenedifluoride Composites. Appl. Phys. Lett. 2002, 81, No. 100.

(40) Ryu, J.; Priya, S.; Carazo, A. V.; Uchino, K.; Kim, H.-E. Effect of the Magnetostrictive Layer on Magnetoelectric Properties in Lead Zirconate Titanate/Terfenol-D Laminate Composites. J. Am. Ceram. Soc. 2001, 84, 2905-2908.

(41) Ryu, J.; Kang, J.-E.; Zhou, Y.; Choi, S.-Y.; Yoon, W.-H.; Park, D.-S.; Choi, J.-J.; Hahn, B.-D.; Ahn, C.-W.; Kim, J.-W.; Kim, Y.-D.; Priya, S.; Lee, S. Y.; Jeong, S.; Jeong, D.-Y. Ubiquitous MagnetoMechano-Electric Generator. Energy Environ. Sci. 2015, 8, 24022408.

(42) Annapureddy, V.; Na, S. M.; Hwang, G. T.; Kang, M. G.; Sriramdas, R.; Palneedi, H.; Yoon, W. H.; Hahn, B. D.; Kim, J. W.; Ahn, C. W.; Park, D. S.; Choi, J. J.; Jeong, D. Y.; Flatau, A. B.; Peddigari, M.; Priya, S.; Kim, K. H.; Ryu, J. Exceeding Milli-Watt Powering Magneto-Mechano-Electric Generator for StandalonePowered Electronics. Energy Environ. Sci. 2018, 11, 818-829.

(43) Nan, C. W.; Liu, G.; Lin, Y. Influence of Interfacial Bonding on Giant Magnetoelectric Response of Multiferroic Laminated Composites of $\mathrm{Tb}_{1-\mathrm{x}} \mathrm{Dy}_{\mathrm{x}} \mathrm{Fe}_{2}$ and $\mathrm{PbZr}_{\mathrm{x}} \mathrm{Ti}_{1-\mathrm{x}} \mathrm{O}_{3}$. Appl. Phys. Lett. 2003, 83, No. 4366.

(44) Bichurin, I.; Petrov, M.; Srinivasan, G. Theory of LowFrequency Magnetoelectric Coupling in Magnetostrictive-Piezoelectric Bilayers. Phys. Rev. B: Condens. Matter Mater. Phys. 2003, 68, No. 054402
(45) Wang, X.; Pan, E. Magnetoelectric Effects in Multiferroic Fibrous Composite with Imperfect Interface. Phys. Rev. B: Condens. Matter Mater. Phys. 2007, 76, No. 214107.

(46) Liang, X.; Dong, C.; Chen, H.; Wang, J.; Wei, Y.; Zaeimbashi, M.; He, Y.; Matyushov, A.; Sun, C.; Sun, N. A Review of Thin-Film Magnetoelastic Materials for Magnetoelectric Applications. Sensors 2020, 20, No. 1532.

(47) Nguyen, T.; Adjeroud, N.; Glinsek, S.; Fleming, Y.; Guillot, J.; Grysan, P.; Polesel-Maris, J. A Film-Texture Driven Piezoelectricity of AlN Thin Films Grown at Low Temperatures by Plasma-Enhanced Atomic Layer Deposition. APL Mater. 2020, 8, No. 071101.

(48) Nguyen, T.; Adjeroud, N.; Glinsek, S.; Fleming, Y.; Guillot, J.; Polesel-Maris, J. Strong Magnetoelectric Effects of 2-2 Composites Made of AlN Films Grown by Plasma-Enhanced Atomic Layer Deposition on Magnetostrictive Foils for Energy Harvesting Applications. Proceedings of the IEEE International Conference on Micro Electro Mechanical Systems (MEMS) 2020, 578-581.

(49) ASTM Designation: D3359-97 Standard Test Methods for Measuring Adhesion by Tape Test; ASTM International, 2010.

(50) Prume, K.; Muralt, P.; Calame, F.; Schmitz-Kempen, T.; Tiedke, S. Piezoelectric Thin Films: Evaluation of Electrical and Electromechanical Characteristics for MEMS Devices. IEEE Trans. Ultrason. Ferroelectr. Freq. Control 2007, 54, 8-14.

(51) Vidal, J. V.; Timopheev, A. A.; Kholkin, A. L.; Sobolev, N. A. Dynamic Measurements of Magnetoelectricity in Metglas-Piezocrystal Laminates. In Nanostructures and Thin Films for Multifunctional Applications: Technology, Properties and Devices (NanoScience and Technology), 1st ed.; Tiginyanu, I., Topala, P., Ursaki, V., Eds.; Springer: Cham., 2016; pp 227-265.

(52) Mos, Y. M.; Vermeulen, A. C.; Buisman, C. J. N.; Weijma, J. XRay Diffraction of Iron Containing Samples: The Importance of a Suitable Configuration. Geomicrobiol. J. 2018, 35, 511-517.

(53) Schneider, M.; Bittner, A.; Schmid, U. Improved Piezoelectric Constants of Sputtered Aluminium Nitride Thin Films by PreConditioning of the Silicon Surface. J. Phys. D: Appl. Phys. 2015, 48, No. 405301.

(54) Akiyama, M.; Kamohara, T.; Kano, K.; Teshigahara, A.; Kawahara, N. Influence of Oxygen Concentration in Sputtering Gas on Piezoelectric Response of Aluminum Nitride Thin Films. Appl. Phys. Lett. 2008, 93, No. 021903.

(55) Vergara, L.; Clement, M.; Iborra, E.; Sanz-Hervás, A.; García López, J.; Morilla, Y.; Sangrador, J.; Respaldiza, M. A. Influence of Oxygen and Argon on the Crystal Quality and Piezoelectric Response of AlN Sputtered Thin Films. Diamond Relat. Mater. 2004, 13, 839842.

(56) Motamedi, P.; Cadien, K. XPS Analysis of AlN Thin Films Deposited by Plasma Enhanced Atomic Layer Deposition. Appl. Surf. Sci. 2014, 315, 104-109.

(57) Alevli, M.; Ozgit, C.; Donmez, I.; Biyikli, N. Structural Properties of AlN Films Deposited by Plasma-Enhanced Atomic Layer Deposition at Different Growth Temperatures. Phys. Status Solidi A 2012, 209, 266-271.

(58) Klokholm, E.; Aboaf, J. The Saturation Magnetostriction of Thin Polycrystalline Films of Iron, Cobalt, and Nickel. J. Appl. Phys. 1982, 53, No. 2661.

(59) Zhou, Y.; Chul Yang, S.; Apo, D. J.; Maurya, D.; Priya, S. Tunable Self-Biased Magnetoelectric Response in Homogenous Laminates. Appl. Phys. Lett. 2012, 101, No. 232905.

(60) Zhou, Y.; Apo, D. J.; Priya, S. Dual-Phase Self-Biased Magnetoelectric Energy Harvester. Appl. Phys. Lett. 2013, 103, No. 192909.

(61) Patil, D. R.; Zhou, Y.; Kang, J.-E.; Sharpes, N.; Jeong, D.-Y.; Kim, Y.-D.; Kim, K. H.; Priya, S.; Ryu, J. Anisotropic Self-Biased DualPhase Low Frequency Magneto-Mechano-Electric Energy Harvesters with Giant Power Densities. APL Mater. 2014, 2, No. 046102.

(62) Greve, H.; Woltermann, E.; Quenzer, H. J.; Wagner, B.; Quandt, E. Giant Magnetoelectric Coefficients in $\left(\mathrm{Fe}_{90} \mathrm{Co}_{10}\right)_{78} \mathrm{Si}_{12} \mathrm{~B}_{10^{-}}$ AlN Thin Film Composites. Appl. Phys. Lett. 2010, 96, No. 182501. 
(63) Sreenivasulu, G.; Mandal, S. K.; Bandekar, S.; Petrov, V. M.; Srinivasan, G. Low-Frequency and Resonance Magnetoelectric Effects in Piezoelectric and Functionally Stepped Ferromagnetic Layered Composites. Phys. Rev. B: Condens. Matter Mater. Phys. 2011, 84, No. 144426.

(64) Jian, L.; Kumar, A. S.; Lekha, C. S. C.; Vivek, S.; Salvado, I.; Kholkin, A. L.; Nair, S. S. Strong Sub-Resonance Magnetoelectric Coupling in PZT- $\mathrm{NiFe}_{2} \mathrm{O}_{4}$-PZT Thin Film Composite. NanoStructures and Nano-Objects 2019, 18, No. 100272.

(65) Palneedi, H.; Choi, I.; Kim, G. Y.; Annapureddy, V.; Maurya, D.; Priya, S.; Kim, J. W.; Lee, K. J.; Choi, S. Y.; Chung, S. Y.; Kang, S. J. L.; Ryu, J. Tailoring the Magnetoelectric Properties of $\mathrm{Pb}(\mathrm{Zr}, \mathrm{Ti}) \mathrm{O}_{3}$ Film Deposited on Amorphous Metglas Foil by Laser Annealing. J. Am. Ceram. Soc. 2016, 99, 2680-2687.

(66) Ghosh, S. K.; Roy, K.; Mishra, H. K.; Sahoo, M. R.; Mahanty, B.; Vishwakarma, P. N.; Mandal, D. Rollable Magnetoelectric Energy Harvester as a Wireless IoT Sensor. ACS Sustainable Chem. Eng. 2020, 8 (2), 864-873. 